\title{
How Can We Support Online Learning for Elementary Students? Perceptions and Experiences of Award-Winning K-6 Teachers
}

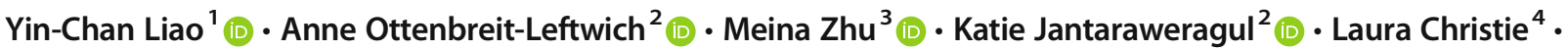 \\ Kandi Krothe ${ }^{5} \cdot$ Katy Sparks ${ }^{6}$
}

Accepted: 30 August 2021 / Published online: 24 September 2021

(C) Association for Educational Communications \& Technology 2021

\begin{abstract}
$\mathrm{K}-12$ online learning can be advantageous in a variety of circumstances, including inclement weather days and emergency remote teaching. With the lessons learned from the COVID-19 pandemic, many K-12 districts may consider ways to incorporate online learning into their regular school plans after they resume face-to-face instruction. However, the most challenges to online learning seemed to take place at the elementary level. This brings up an important question: What should elementary online teaching and learning look like? We examined six award-winning K-6 teachers' perspectives on and experiences with online instruction and practices for elementary students. The teachers suggested that online instruction to support elementary students' learning should be (a) organized, (b) engaging, and (c) interactive. Teachers also suggested that developmentally appropriate use of technology and parental involvement may foster elementary students' online learning experiences.
\end{abstract}

Keywords Elementary education $\cdot \mathrm{K}-12$ schools $\cdot$ Online course design $\cdot$ Online learning

The unprecedented COVID-19 pandemic significantly impacted teaching and learning in K-12 schools in the United States, forcing many schools to close and move online during the 2019-2020 school year and beyond (Dibner et al., 2020; Education Week, 2020). Although many students' learning was disrupted, K-12 teachers, students, and parents have had a new perspective of teaching and learning that includes an increased recognition of the importance of using digital learning in $\mathrm{K}$ 12 education (Project Tomorrow, 2020b). Schools may

Yin-Chan Liao

liaoy19@ecu.edu

Anne Ottenbreit-Leftwich

left@iu.edu

Meina Zhu

meinazhu@wayne.edu

Katie Jantaraweragul

katemart@iu.edu

Laura Christie

lchristie@hse.k12.in.us also rethink K-12 education structures and incorporate more online learning into their regular school plans even after the pandemic.

$\mathrm{K}-12$ online learning gained widespread attention this past year; however, it has been in use since well before the COVID-19 pandemic. In 2016, millions of K-12 students took supplemental online courses for recovering credits or advanced placement while attending a traditional school (Germin \& Pape, 2017). Project Tomorrow (2020a) surveyed 343,500 K-12 students, parents, and

Kandi Krothe

kkrothe@theprojectschool.org

Katy Sparks

kesparks@mccsc.edu

East Carolina University, Greenville, NC, USA

2 Indiana University, Bloomington, IN, USA

3 Wayne State University, Detroit, MI, USA

4 Sand Creek Intermediate, Fishers, IN, USA

5 The Project School, Bloomington, IN, USA

6 Highland Park Elementary School, Upper Darby, PA, USA 
staff and found $48 \%$ of administrators indicated that online classes were available to their students during the 2018-19 school year. There are multiple rationales for K-12 online learning, including flexibility and accessibility of learning (Digital Learning Collaborative [DLC], 2020). Many K-12 school districts have integrated eLearning days as a method of continuing teaching and learning for teacher professional development days, inclement weather days, or unplanned school closures (e.g., DLC, 2020; Fox \& Jones, 2019). Since online learning provides additional learning opportunities for students, understanding the design and practice of online learning becomes crucial for increasing its effectiveness.

\section{Statement of the Problem}

Teachers continue to struggle to teach in fully online or blended courses, especially at the elementary level (Project Tomorrow, 2020a). DeWitt (2017) reported three primary challenges for online K-12 teachers. First, it was challenging to scaffold students' use of technology, particularly with young students. As a result, teachers had to help them learn how to use technology tools or apps in an online environment. Second, teachers who were new to online teaching required justin-time support and resources when they encountered technical problems. Third, teachers described that the time needed to prepare lessons was extensive (DeWitt, 2017).

Overall, research on teachers' perspectives and practices of K12 online teaching and learning, especially at the elementary level, was less comprehensive (Arnesen et al., 2019; Lin et al., 2017). Although research in the field of K-12 online learning is growing rapidly, there is a lack of empirical studies conducted at the elementary level with evidence on how to support online learning design and practices (Arnesen et al., 2019; Barbour, 2019). Furthermore, it is unclear how much of the knowledge and findings from the secondary online learning literature are applicable to the elementary school contexts. Therefore, the purpose of the study was to explore which essential components teachers should consider in their online instruction to support elementary students' online learning. We examined a group of technology-savvy, award-winning online K-6 teachers' perspectives and experiences of online teaching in elementary schools by asking the following research questions:

1. What did award-winning online $\mathrm{K}-6$ teachers perceive as essential for online instruction at the elementary level?

2. How did award-winning online K-6 teachers support their elementary students' online learning?

\section{Literature Review}

Successful online learning is not guaranteed for all K-12 students (Lee \& Figueroa, 2012). In a review of literature, Cavanaugh (2013) identified factors of K-12 online education affecting student achievement, including (a) student characteristics, (b) course design, (c) instructional factors, (d) technological approaches, and (e) administrative practices. The author concluded that student learning can only be effective in both online and traditional K-12 elementary and secondary classroom environments only when the courses are well designed. In secondary school contexts, online instruction is effective for high school students when teachers (a) use a learner-centered approach, (b) design tasks that interest students, (c) have clear course organization and structure, and (d) integrate multimedia to engage students (Oliver et al., 2009). Farmer and West (2019) employed interpretative phenomenological analysis to generate an in-depth understanding of seven secondary teachers' concerns of online teaching. In the findings, three major themes were identified as concerns about online teaching: personal (e.g., expectations, time management), instructional (e.g., course quality, technology), and relational (e.g., experiences of students and mentor) concerns.

Interaction is fundamental for both traditional, face-to-face classrooms and online learning (Moore, 1989; Swan, 2001). Farmer and West (2019) suggested that K-12 teachers should incorporate learning activities that elicit student interactions into their online course designs. Encouraging interaction among students in online learning settings can help develop students' critical thinking skills (Wagner, 1997), foster deep learning (Anderson, 2003), and enhance cognitive development and student motivation (Borup et al., 2013). In the context of high school online language courses, Lin et al. (2017) surveyed 466 students to examine how different types of interactions affect students' learning satisfaction and progress. The results showed that the ways high school students interacted with learning materials and activities positively affected their learning achievement and satisfaction.

The relationship and communication between online students and teachers has also been found to impact completion rate (Hawkins et al., 2013), motivation (Murphy \& Rodriguez-Manzanares, 2009), sense of belonging (Borup et al., 2014b), academic performance (Burdina et al., 2019), and satisfaction (Lin et al., 2017). Building relationships with students while managing learning can be challenging for teachers, which can be especially difficult in an online environment (Muirhead, 2000). Velasquez et al. (2013) examined two high school teachers' online practices and tools used to facilitate a caring approach of teaching while mediating their interactions with students. The results indicated that technologies should be accessible and enable continuous dialogue and shared teacher-student experiences in online environments. Teachers' use of online learning technologies also 
should allow for open communication, allowing teachers to identify students' needs through observation. Linton (2016) conducted a case study examining ways online learning communities support teachers in developing relationships with high school students at a virtual school. The results suggested that teachers' involvement in online learning communities allowed them to share best practices for communication and building relationships with students. Students were also encouraged to build a learning community that yields collaborations in high school online learning settings.

$\mathrm{K}-12$ student engagement is essential to successful K12 online learning (Borup et al., 2014b; Velasquez et al., 2013). Borup et al. (2014b) suggested that encouraging ownership of learning is one way to engage students in online learning. Moreover, Avery et al. (2021) suggested several tips for engaging K-12 students in online learning: (a) provide clear communication through multiple formats, (b) mix asynchronous and synchronous activities, (c) use competency-based learning, (d) engage families, (e) design for student interests, (f) include assessments throughout learning, and $(\mathrm{g})$ provide differentiation of learning. Velasquez et al. (2013) found high school students valued a shared experience where they could work collaboratively with their teachers in technology-mediated online environments (e.g., Google Docs, Skype). Appropriate technology tools allowed teachers to observe and monitor students' engagement and needs. Therefore, teachers play an essential role in student engagement in online learning. Online teachers should aim to become facilitators of learning and balance the control of learning between student and teacher (Borup et al., 2019; Farmer \& West, 2019).

To support online learning at the elementary level, Lee and Figueroa (2012) emphasized the importance of parental involvement in K-6 students' online learning process because of students' lack of independence. The authors suggested different types of support parents can provide (e.g., communication between student and teacher, monitoring learning progress, encouraging students to have positive attitudes) to help students succeed in online learning. Burdina et al. (2019) studied 430 students aged 8-9 years across the Republic of Tatarstan to explore their online learning experiences in elementary classrooms. The study reported elementary students needed facilitators or teacher support along with timely student-teacher communication to be successful in online learning.

The majority of K-12 online learning literature is focused on secondary school contexts. Because of the significant increase in K-12 online learning, there is a need for adding more research in elementary school contexts to understand ways to support online teaching and learning with evidence from teaching practices.

\section{Method}

To answer the research questions, we employed a qualitative approach of inquiry to explore a group of K-6 teachers' perspectives and experiences of online learning.

\section{Context and Participants}

Seven recipients of an elementary educator award for excellence in technology integration were recruited in Summer 2020. All seven teacher awardees participated in this study as a cohort. The teachers applied for the award with a video showcasing their online instruction with effective and innovative technology uses to support student learning at the elementary level, from kindergarten to Grade 6 . A committee of nine university faculty and staff members evaluated applications with a prescribed rubric, and each application was reviewed by three committee members. Applicants with the highest number of points were selected as recipients of the award.

The teachers' teaching experiences varied (see Table 1). Their schools had a range of moderate to high socioeconomic status (SES) students with adequate technology resources. All schools had some version of one-to-one technology resources for teachers and students.

As award recipients, the teachers were involved in an award program that required monthly meetings. Each meeting involved two parts: a focus group discussion about effective online learning and co-design activities. The teachers codesigned an online learning module template with their grade-level partners based on the discussions and then shared it with the cohort. The researchers provided examples and answered questions during the co-design time. The goal of the monthly meetings was to produce online modules and lesson plans for other elementary teachers who teach online or need resources for emergency remote teaching. This study was the first part of the award program focused on exploring what teachers considered important in online instruction at the elementary level based on their experiences (see Fig. 1).

In the first two months, the researchers introduced the project goals and facilitated cohort discussions on successful online instruction. Then, teachers were assigned to grade band groups (Kindergarten - Grade 2, Grade 3 - Grade 4, and Grade 5 - Grade 6) for communication and co-design activities through the rest of the program. The researchers had a monthly meeting with each grade band group to facilitate discussion and reflection on their lesson plans and module co-design projects.

\section{Data Collection}

The data sources included audio recordings and documents from the focus groups $(n=8)$. Documents included a Google Jamboard slide and a Padlet board where teachers 
Table 1 Teacher Participant Demographics

\begin{tabular}{lllll}
\hline $\begin{array}{l}\text { Teacher Name } \\
\text { (pseudonym) }\end{array}$ & Grade Level & $\begin{array}{l}\text { Years of Teaching } \\
\text { Experience }\end{array}$ & $\begin{array}{l}\text { Economically } \\
\text { Disadvantaged (\%) }\end{array}$ & $\begin{array}{l}\text { School } \\
\text { Area }\end{array}$ \\
\hline Lily & $\mathrm{K}$ & 5 & 32.3 & Rural \\
Anita & $\mathrm{K}$ & 9 & 27.0 & Rural \\
Katrina & $3 / 4$ & 19 & 30.0 & Suburban \\
Kelly & $4 / 5$ & 8 & 56.9 & Rural \\
Lola & 5 & 18 & 22.4 & Suburban \\
Kim & 6 & 8 & 30.0 & Suburban \\
Lawrence & K-6 Technology Coach & 13 & 44.7 & Rural \\
\hline
\end{tabular}

typed their answers to some focus group questions (Appendix A). As shown in Fig. 1, we conducted two whole-group meetings in the first two months, followed by six grade-band group meetings (two for each grade band). In the focus groups, two researchers led discussions and asked follow-up questions to discover teachers' perceptions and experiences of elementary online instruction with examples and explanations. Each meeting was approximately two hours and recorded using the Zoom online video conferencing tool.

Additionally, we collected teachers' online instruction example videos $(n=7)$ submitted as application material for the technology educator award application. The teachers also shared with us the instructional materials (e.g., presentation slides, instructional videos) they included in their example videos. All data were digital and stored in a private Google Drive folder.

\section{Data Analysis}

We employed grounded theory analysis (Charmaz, 2006) to discover what award-winning teachers considered essential in online instruction to support elementary students' learning. Using grounded analysis of data to generate substantive concepts that emerged from the data allowed us to explore teachers' elaborated reasoning and thoughts. With this analysis approach, we could expand on differences from what is already known in the K-12 online learning literature (Charmaz, 2006).

Fig. 1 Timeline of the Award Program and the Focus of the Study
Through open coding, the first author established our initial codes and categories from two focus group transcripts and texts in Jamboard and Padlet activities. While more focus group recordings were being collected during the coding process, the refinement of codes and categories continued as an iterative process. Three members of the research team identified codes representing teachers' online instruction perceptions and practices and synthesized categories by sorting and resolving coding discrepancies through discussions. Once all the data were collected, the researchers familiarized themselves with the data. Lastly, they discussed their understanding and interpretations of the data to finalize the core concepts and the relationships of different codes. Using multiple data sources and approaches to collect data over time helped us triangulate the data to increase the trustworthiness of the results (Kolb, 2012).

\section{Results}

This study aimed to examine award-winning K-6 teachers' perceptions of essential components in online instruction at the elementary level based on their teaching experiences. The results showed that award-winning teachers perceived course organization, student engagement, and variants of interaction as essential components in online instruction to support students' online learning at the elementary level. Examples of how the teachers supported their elementary

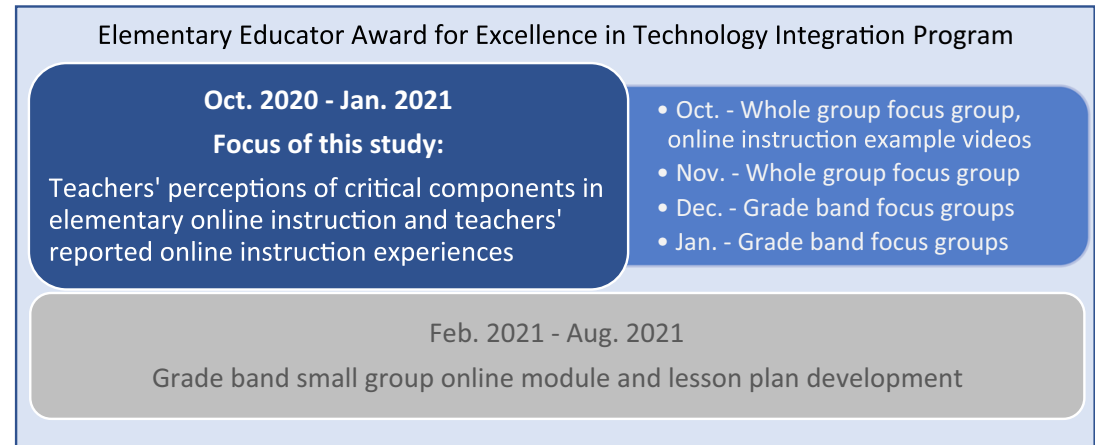


students' online learning are presented in the description of each essential component.

\section{Organization}

All participating teachers expressed that having organized online instruction that includes consistent course design and management is essential, especially when facilitating elementary students' learning in a virtual environment. Additionally, the teachers described the accessibility of course content and resources as the key to establishing students' daily learning routines.

Kim shared that a class website can be a learning hub for easy navigation of online learning resources: "I have a class website that I use to provide a daily task list, a weekly task list, and links to different Google Classrooms/Zoom links students may need." Lola organized her daily lessons using the $5 \mathrm{E}$ framework to provide a smooth learning flow for her students (see Fig. 2). Using this framework, Lola was able to help students establish learning routines in the following process: (a) engaging students in a learning topic through a hook activity and student exploration, (b) explaining learning content with the support of tools and resources, and (c) facilitating student application of knowledge and reflection on the overall learning experience. Lola also created a daily learning agenda to prepare students for online learning (see Fig. 3): "I use the same agenda for the day. It streamlines everything for easy transitions for online materials and lessons. The agenda can have our schedule and video directions for the day."

Katrina used colors to create an organization in her fourthgrade math materials. Students began on yellow background slides with her walking them through these examples, and then students progressed to independent practice on the green slides. Students could then challenge themselves with rainbow-colored slides at the end (see Fig. 2). At the lower elementary level, Lily expressed the importance of using consistent slides every day that walked students through the daily activities, particularly when students were forced to be at home due to illnesses or quarantine procedures. She explained, "I believe online learning is most effective when it is accessible to all students and closely mirrors the instruction that would take place in the physical classroom. Technology can be overwhelming to parents, students, and teachers." Thus, having consistency in learning tools and materials can help decrease elementary students' learning challenges in a hybrid or online environment. Figure 2 shows the design of the slides Lily used to provide consistency should students change between in-person and virtual learning.

\section{Student Engagement}

All teachers emphasized that online instruction would not be successful without engaging elementary students in the learning process. From the teachers' experiences, students were more engaged in online learning when teachers integrated (a) authentic learning experiences with choices and (b) ageappropriate technology tools and resources.

\section{Authentic Learning Experiences with Choices}

Regardless of grade level, teachers agreed that getting students excited about learning and engaged in the learning process was essential in online learning. One way to promote student engagement was by connecting learning content and contexts to students' lives and interests. For instance, Lily created a classroom cafe as an authentic learning context for her kindergarten students to apply what they learned: "Students wrote their books with sight words and pattern words, then sell their books to peers at our classroom coffeeshop. That was a fun activity with something relevant and shareable." Anita described that providing choices helped to engage her kindergarteners: "The way I have seen the most engagement and interaction in assignments is giving a choice to families and making lessons hands-on with accessible resources." Both kindergarten teachers emphasized that online learning should not be a checklist for kindergarten students to complete.

All teachers found project-based learning an effective way to engage students in authentic learning topics and provide them choices to create artifacts in a virtual learning environment. For instance, Kim always found that having students tell personal stories to connect real-life and classroom contexts helped student engagement. In another example, Kelly designed a maker challenge for her fourth-grade students to respond to the COVID-19 pandemic with a driving question: How can we improve the people's lives in [our town] during a pandemic? Within this project, Kelly built-in choices for students to select their own topics and the product they would make (e.g., physical innovation out of LEGOs, writing a paper, making a stop-motion video, creating a Google Slides presentation, or an advertisement). Project-based learning seemed to appeal to the teachers because it allowed for creativity, flexibility, and choices to engage elementary students in the learning process and enhance their online learning experience.

\section{Age-Appropriate Technology Tools and Resources}

The teachers reported that online instruction needs to include manageable and age-appropriate technology tools and resources to support students' learning mechanisms and engagement. Kim reflected on her online instruction and encouraged other teachers to "pick tools that most students can intuitively operate or need little direction to navigate unless they are using them synchronously and we [teachers] can walk them through it."

Some teachers highlighted the importance of having fewer clicks and using only a few primary technology tools to avoid overwhelming students. Lily described, "Especially in kindergarten, it is important that the technology we choose to 


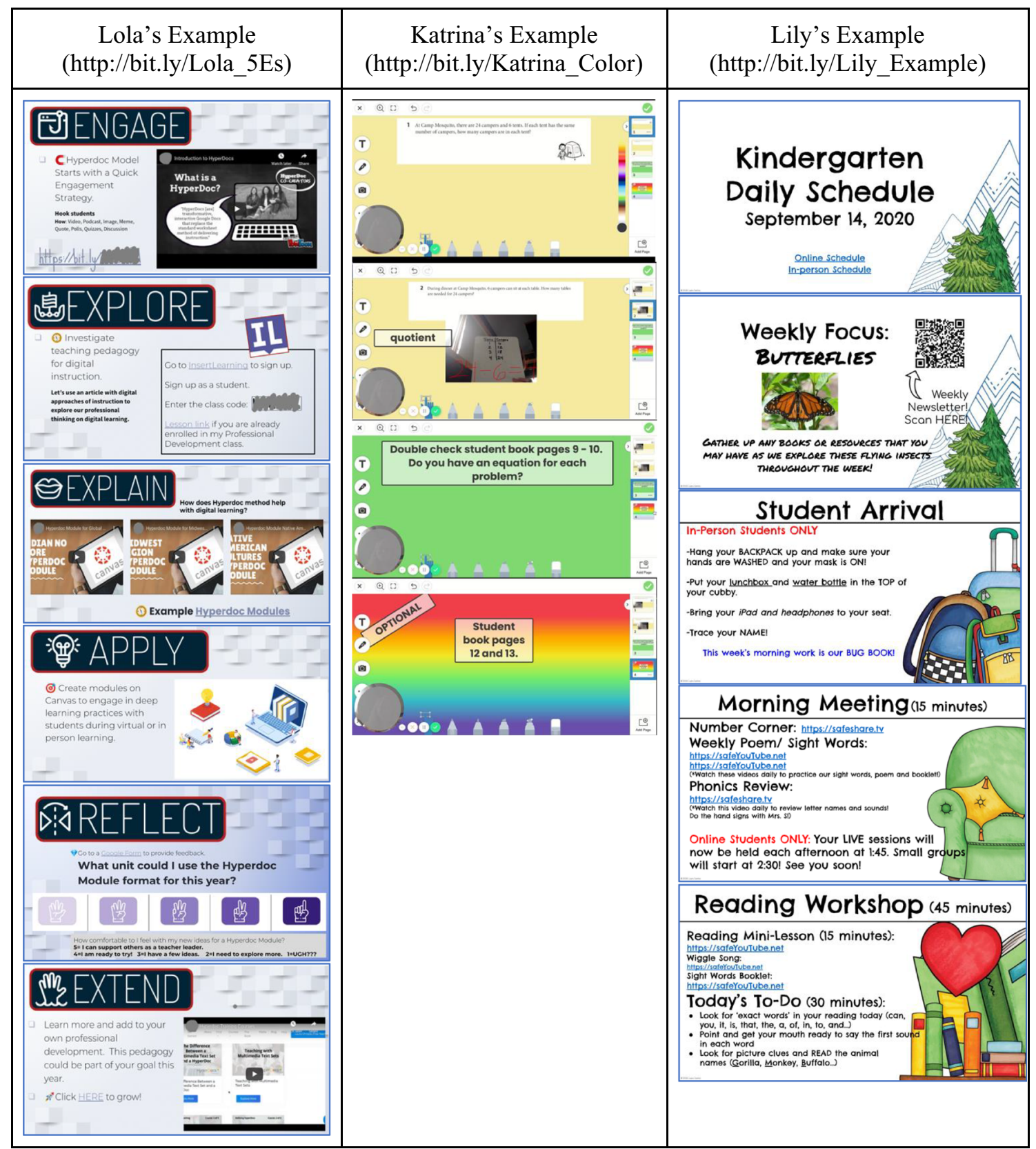

Fig. 2 Examples from Teachers' Teaching Materials

incorporate into our instruction is age-appropriate and can be easily navigated by both parents and students." Fourth-grade teachers, Katrina and Kelly, suggested that teachers use adaptable online teaching tools that can be applied across subject areas, such as Flipgrid and Edpuzzle. Using consistent and appropriate online teaching tools allows students to focus more on learning the content rather than continuously learning how to use new tools.

As a K-6 technology coach, Lawrence argued, "The more clicking to something else for students, the more confused they get." This argument was shaped based on Lawrence's teaching experience:
At times I saw my students cry as kindergarteners and first graders to get through e-learning. So, when I design and train my teachers to design, I keep that in mind that there are children who do not have a support system. Because of that, we have to make online learning streamlined but at the same time have quality tools.

\section{Variants of Interaction}

The teachers perceived that interacting through (a) teacher facilitation and support, (b) peers, and (c) parental 
Fig. 3 Example of Lola's Agenda Slide

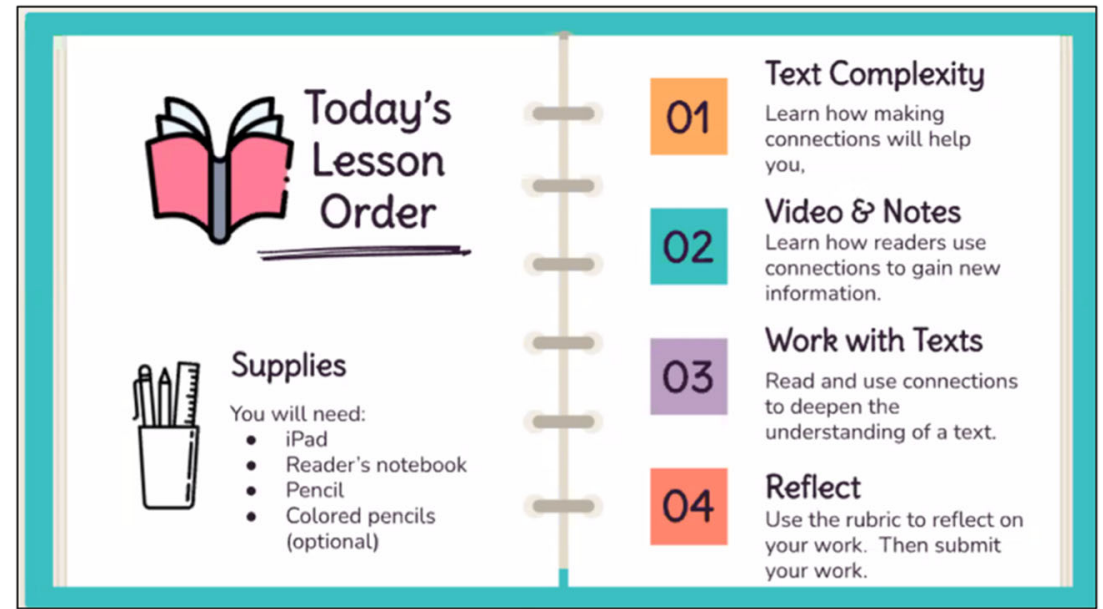

involvement was essential in online instruction to foster elementary students' online learning.

\section{Teacher Facilitation and Support}

Since students at the elementary level are not as independent as students at the secondary or post-secondary level of learning, the teachers described a need for teacher facilitation to make online learning more effective and interactive for elementary students. The teachers perceived that having recorded videos of modeling and showcasing learning content or activities is an effective way to help students understand concepts and stay on task. The recordings allowed students to follow along or revisit the instruction as needed. Kim reported that she would "make sure that the learning goals and targets are shared while trying to show modeled work to make learning explicit." Towards the end of each online lesson, Kim would wrap up "by facilitating a student reflection on the skills and progress towards them."

Anita, a kindergarten teacher, pointed out that teacher facilitation was particularly important in teaching a subject that needs a dynamic learning environment such as math: "Teachers need to monitor the learning process and see what students are thinking and how they are solving problems to reflect on how to do differently in their instruction to support student learning." To support fifth-grade students' online learning, Lola used the tool "Classkick to monitor students' pairing activities and overlooked what each student was working on to provide immediate feedback simultaneously or offline."

The teachers indicated that they typically scheduled a combination of whole group, small group, and individual online meetings throughout the day, depending on the learning contexts and objectives, to facilitate and support student learning. For instance, Kim would host whole group meetings for sixth-grade math: "I teach the whole group for math using tools like Pear Deck \&
Desmos. I can see students draw out their work, fill in a variety of types of questions, and get feedback in real-time." In Kelly's fourth-grade class, she would host a whole group meeting in the morning and smaller group meetings and office hours in the afternoon to engage with her students. Anita further suggested that after her kindergarten students got into the online learning routines and familiar with the online learning environment, she was able to "release learning responsibility gradually to students." The data showed that teachers' facilitation of learning and individualized support were particularly essential for lower grade level students getting into the learning routine and involved in an online learning environment.

\section{Interaction among Students}

All teachers expressed that students' interaction and collaboration were key in online learning. Upper elementary teachers indicated that online learning collaboration seemed to work for their students because of their language and digital literacy skills. Both Lola and Kim used Padlet for student online interactions and collaboration. Lola had her fifth-grade students use Padlet to add pros and cons in breakout rooms when they were exploring a new topic and found, "Students seeing feedback from peers is beneficial." Kim also described the benefits of online collaboration for her sixth-grade students: "In the community building realms, moving away from teacherdirected activities and into student interest-based groups has been a game-changer for my students."

The lower elementary teachers described the importance of creating opportunities for students to interact with each other by sharing their work online. For instance, Lily explained, "Students usually don't get to know their friends very well in an online environment. So, pairing students up or having them share something with peers can get students excited and motivated." 


\section{Parental Involvement}

Teachers of all grades considered the importance of involving parents, which tended to break down into two categories: parents as assistants and parents as co-teachers. Most of the upper elementary teachers described parents as assistants. In this role, parents helped their students submit assignments and get to meetings on time. Most of the lower elementary teachers described parents as co-teachers. In this role, parents would facilitate learning experiences and review content. Regardless of how much parents were involved in student learning, the teachers found that building a relationship and providing ways to communicate with parents during online instruction was critical and necessary. Anita explained based on her experience in kindergarten:

To build that trusting environment, you must build a relationship with the families and students. Building relationships from afar isn't as easy. I've found that checking in regularly with families in a variety of formats gives them a voice, and I needed feedback to create content to meet their needs.

When parents play the role of a co-teacher, they need to understand the intended learning objectives or goals for each lesson. Anita suggested, "Teachers need to provide instruction for students and parents. The learning tasks should be practical and easily attainable. Also, teachers need to set an end goal and help families with the steps to get to that goal" (see an example in Fig. 4). At the fifth-grade level, Lola described hosting one-on-one meetings with each student and parents at the beginning of the school year to establish a relationship and identify the goals for the year.
Kim stated, "An absence of parental involvement can make online instruction more challenging." However, to involve parents, the teachers described a need to prepare additional materials. In kindergarten, Lily made sure to use the same slides and format she used in her face-toface instruction for her online students. She provided additional instructions to guide parents as they reviewed learning content and tasks with their kids. Kelly also provided an example of the way she prepared the parents for their involvement:

Parents are all rostered [in] my Canvas course so they could see anything. I send weekly email newsletters and sometimes include YouTube tutorials that I've created to explain new math. Like I sent a partial quotient lesson that I did with my students out to parents last week so they could support their kids.

Enabling ways of communicating with parents could help establish the teacher-parent trust and relationship, further supporting students' online learning. For instance, Kelly sent out weekly email newsletters to inform parents of the learning schedule. Lola scheduled routine meetings with parents. To receive parents' opinions and feedback, Lawrence created a short survey using Google Forms for regular checks. In a kindergarten class, Anita created a private Facebook group for interaction and communication with parents. When communicating with parents, the teachers stressed that teachers should focus on the crucial points and not overwhelm them with too much content or information. Overall, these teachers described the importance of taking parental involvement into account when planning and designing online instruction for students at the elementary level.
Fig. 4 Example of Learning Goals Shared with Parents in Anita's Class

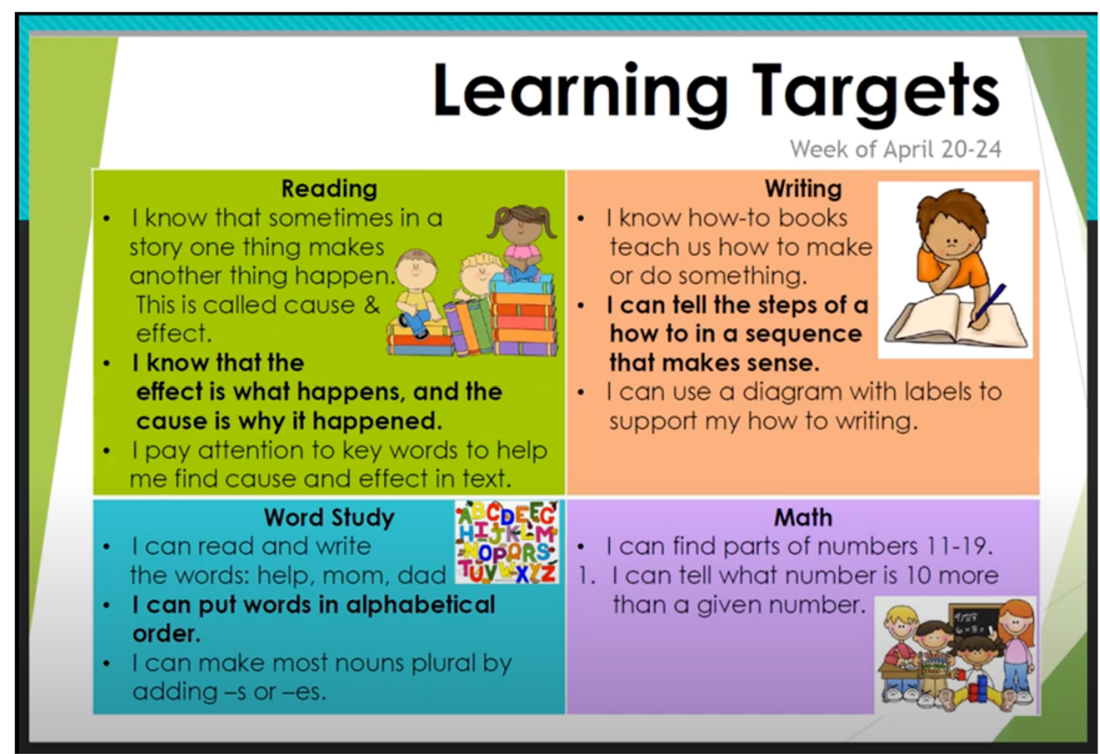




\section{Discussion and Implications}

While most existing empirical studies on $\mathrm{K}-12$ online instruction were conducted at the secondary level (e.g., Arnesen et al., 2019; Borup, 2019), the results of this study provide some knowledge of online instruction at the elementary level to fill the gap in the existing literature. We discuss below how the results of this study relate to the literature and provide implications for research and practice.

\section{Ideas Consistent with Existing Online Education Literature}

The results showed that award-winning elementary teachers perceived the importance of addressing (a) organization, (b) student engagement, and (c) variants of interaction in online instruction to support students' online learning. These components of online instruction are aligned with existing recommended online education practices identified in the literature.

\section{Organization}

Teachers in this study perceived the importance of organization in online instruction to allow students and parents to navigate learning materials smoothly and limit challenges and frustration due to disorganization. Many of these teachers utilized a template and consistent daily schedules to provide predictability and regularity of learning content and activities to support students' online learning experiences, which are strategies that are consistent with prior research on self direction in online learning environments (Zhu \& Bonk, 2019). In Borup et al.'s (2014b) Adolescent Community of Engagement framework, students' engagement is positively correlated with teacher engagement, which includes providing students an organized online learning schedule and environment.

Preparing organized online instruction may not be easy for elementary teachers in traditional school contexts. Some teachers have reported that a lack of just-in-time support during teachers' online learning curriculum development and limited preparation time caused online teaching challenges (DeWitt, 2017). The dramatically quick switch to online learning in March of 2020 also evidenced the need for teacher support in K-12 online instruction (Project Tomorrow, 2020a). Elementary teachers across the United States described struggling with moving to online learning environments without the necessary time and support (Fauzi \& Khusuma, 2020; Schleicher, 2020). Future practices should dedicate more time and support to teachers as they develop online teaching and learning experiences. When teachers are more prepared to teach in online and blended environments, they are more likely to provide equitable and effective teaching and learning (Darling-Hammond et al., 2020). What and how to support elementary teachers' online instruction should also be further examined.

\section{Engagement}

The engagement of students in online learning has been a heavily discussed topic at all grade levels. Giving K-12 students autonomy in online learning can help engage students because they are likely to feel ownership and responsibility for their learning (Farmer \& West, 2019; Lee et al., 2015). The participating teachers used different ways to support student autonomy with their students that resonated with the literature, such as learning choices and hands-on opportunities that allowed students to apply learned knowledge and skills in authentic contexts (Oliver et al., 2019). This way, students may feel the relevance and the value of the learning content, consequently spending more time and effort on the activities (Lee et al., 2015). The kindergarten teachers also provided opportunities for students to showcase their work to peers and reflect on their learning experiences in small groups online. Consistent with prior research (e.g., Cavanaugh et al., 2009; Linton, 2006), encouraging students to have social interaction and peer support helped increase their online learning engagement.

Teachers may need to consider the appropriate amount of ownership they release to students at the elementary level when providing learner-centered online learning with flexibility and choices for students. Teachers might consider: How many choices and options should teachers give that will not overwhelm students? How much guidance and scaffolding do teachers provide while releasing ownership to students that keeps them challenged and motivated in online learning?

\section{Interaction}

Our elementary teachers found the importance of teacherstudent interaction and the interaction among students in an online environment to be a critical factor in increasing students' online learning motivation (Murphy \& RodriguezManzanares, 2009), cognitive development (Burdina et al., 2019), and engagement (Borup et al., 2014a). These results are not surprising. From a social-cultural perspective of student learning (Salmon, 2011; Vygotsky, 1978), human interaction matters regardless of a physical or virtual learning environment.

Although the elementary teachers perceived the importance of online learning interaction, they expressed the difficulties of enacting it in asynchronous situations. In synchronous online sessions, the teachers could facilitate whole-group and breakout room activities where students could receive instant feedback and express their thoughts with the teacher and other students (Wicks, 2010; Zhu \& Bonk, 2019). In asynchronous online sessions, the teachers facilitated learning interaction through pre-recorded instructional videos, guided materials, and interactive online tools; however, human interaction was limited. Although the teachers integrated optional meetings or 
sent emails to check in with students and parents for asynchronous sessions, they found the synchronous format more attainable to address elementary students' needs in online learning. Researchers stressed that limited interaction among students might cause a negative influence on students' learning experiences (Weiner, 2003). To increase elementary students' interaction and engagement in online learning, a combination of support from the online teacher and on-site facilitators (i.e., mentors who assist and monitor students' learning progress) in classrooms may be an attainable option (Borup et al., 2019).

\section{Unique Considerations for Elementary Online Instruction}

We identified two unique aspects that elementary teachers might need to take into consideration in their online instruction: developmentally appropriate use of technology and parental involvement.

\section{Developmentally Appropriate Use of Technology}

Using developmentally appropriate technology tools and learning resources was one of the elementary teachers' primary considerations when developing their curriculum. For instance, from a cognitive development perspective, young students understand math concepts better using appropriate physical manipulatives along with teachers' side-by-side instruction (Willingham, 2017). This might be difficult for teachers to directly transfer what students do in the classroom to an online learning environment. Therefore, when teaching online, teachers need to be mindful of ensuring the use of technology tools and resources based on the content, the context, and the needs of young students (Guernsey, 2012). How to teach and support students, especially young students, to use digital resources or apps in an online learning environment was identified as a challenge in online instruction (DeWitt, 2017). Thus, to help elementary teachers overcome online instruction challenges, demonstrating different strategies with online learning facilitation examples and providing ready-toadopt resources may be effective ways to address teachers' professional learning needs.

\section{Parental Involvement}

The relationship and collaboration between teachers and parents in online learning was heavily emphasized in the study results. This is a unique perspective from what is typically highlighted in the literature on K-12 online education. The reason is likely due to the limited literature on online learning at the elementary level before 2020. Since the COVID-19 pandemic began in early 2020 , more attention has been given to online learning at the elementary level due to the pressing need for emergency remote teaching with a rapid transition from face-to-face to online learning (Fauzi \& Khusuma, 2020). Parental involvement in young students' online learning has become even more prevalent during the emergency remote teaching period (Avery et al., 2021; Kim, 2020; Project Tomorrow, 2020a). In early elementary online learning, instructor responsibilities have extended beyond the teacher to include parents and families. Instead of replacing teachers, parents serve as important stakeholders to stay involved and engaged in $\mathrm{K}-12$ online learning (Borup et al., 2014b).

There was a continuum of parental involvement for different students' needs in online student learning, ranging from parents as co-teachers at the lower elementary to parents as assistants at the upper elementary level. Lower elementary students may need additional assistance from parents to understand the learning content during online instruction and review it afterward for tasks and assignments. In comparison, upper elementary students may ask for parents' assistance in the learning progress when needed. All teachers in this study expressed a need for parent training on the functions of online learning tools and additional guided materials to show parents the learning objectives, expectations, and strategies to support their children's learning, which echoes the importance of parental engagement in elementary students' online learning (Lee \& Figueroa, 2012).

In the Teacher Digital Learning Guide published by the U.S. Office of Educational Technology (2021), parental involvement is one of the key recommendations to support student learning in leveraging digital tools and resources. It includes teachers' relationship-building and two-way communication with parents to allow teachers to convey learning expectations and provide social and emotional support for students. Similarly, when talking about using technology in learning with young learners, one of the guidelines proposed by the U.S. Office of Educational Technology is to use technology, such as video conferencing tools, to "strengthen relationships among parents, families, early educators, and young children" (Lee, 2016, p. 14). Thus, a healthy relationship and smooth communication between teachers and parents should be well-established for successful elementary students' online learning (Avery et al., 2021; Curtis \& Werth, 2015; Velasquez et al., 2013).

\section{Limitations and Future Research}

We recognize that the design and development of online instruction should be based on each teacher's specific instructional context (Murphy et al., 2011). The participating teachers were from middle to high SES school districts in Indiana, which means that their schools were more likely to have resources and support for online learning (Aikens \& Barbarin, 2008). Therefore, the results of this study might be more applicable to teachers who teach in a similar school 
context. We provided diverse perspectives and examples from teachers across elementary grade levels; however, we were unable to include diverse instructional contexts in this study. In addition, the study results were based on self-reported data even though we collected multiple data sources to increase the trustworthiness of the results. We had limited access to observe teachers' actual online instruction practices as the study was conducted during the COVID-19 pandemic. These limitations create a need for further research to dig deeper into online instruction at the elementary level.

\section{Conclusion}

The purpose of this study was to explore some essential components teachers should take into consideration in their online instruction to support students' online learning in traditional elementary education contexts. At some point, the COVID-19 pandemic will be over, and online learning will likely recede to a lower priority for K-12 schools. However, the essential components of online teaching and learning identified in research studies are likely to stay relevant for face-to-face K-12 education. The results of this study can be implemented through e-Learning Days, teacher professional development days, snow days, or even lessons taught by substitute teachers. These results can also be applied when elementary teachers use technology tools and digital learning resources in their classrooms for course organization, student engagement, and interaction. Future research can explore how elementary teachers might design online instruction and facilitate student learning differently in different subject areas and school contexts.

\section{Examples of Focus Group Questions}

Focus Group \#1 and \#2

- What makes good online instruction?

- What does an e-learning design template need?

Focus Group \#3, \#4, and \#5

- What did you notice from some exemplary online instruction?

- What does a daily and consistent schedule look like?

- What open-ended tools would be best to focus on?

- What are the needs of the learners?

- What does product versus process learning look like for your age group and online learning?

- How would this be adapted for eLearning days in the future?
Focus Group \#6, \#7, and \#8

- Can you briefly describe why it is important to organize online learning and how you do that?

- How do you engage your students in online learning?

- How do you facilitate student learning (whole group, small group, individualized)?

- How have you designed your online modules to involve parents (or how do you partner with parents, or what are the expectations for parents?)

Funding Partial financial support was received from the Barbara B. Jacobs fund at the Indiana University School of Education for the data collection in this research project.

\section{Declarations}

Ethics Approval This study was reviewed by the Human Subjects and Institutional Review Boards of Indiana University and received expedited approval.

Financial Interests The fourth author has received research support from the Barbara B. Jacobs fund and served as a research assistant in the Barbara B Jacobs program.

Non-financial Interests The second author is the Barbara B. Jacobs Chair in Education and Technology within the School of Education at Indiana University - Bloomington and receives no compensation as the Chair of the Jacobs program.

\section{References}

Aikens, N. L., \& Barbarin, O. (2008). Socioeconomic differences in reading trajectories: The contribution of family, neighborhood, and school contexts. Journal of Educational Psychology, 100(2), 235251. https://doi.org/10.1037/0022-0663.100.2.235

Anderson, T. (2003). Modes of interaction in distance education: Recent developments and research questions. In M. G. Moore, \& W. G. Anderson (Eds.), Handbook of distance education (pp. 129-144). Lawrence Erlbaum Associates.

Arnesen, K. T., Hveem, J., Short, C. R., West, R. E., \& Barbour, M. K. (2019). K-12 online learning journal articles: Trends from two decades of scholarship. Distance Education, 40(1), 32-53. https://doi. org/10.1080/01587919.2018.1553566

Avery, L., Jones, M., Marr, S., \& Wenmoth, D. (2021). Mere engagement: Reflections about the connections between online learning, student agency, and student engagement. Aurora Institute. https:// aurora-institute.org/wp-content/uploads/Mere-Engagement-web. pdf

Barbour, M. K. (2019). The landscape of K-12 online learning: Examining the state of the field. Handbook of distance education, 521-542.

Borup, J., Chambers, C. B., \& Stimson, R. (2019). K-12 student perceptions of online teacher and on-site facilitator support in supplemental online courses. Online Learning, 23(4), 253-280.

Borup, J., Graham, C. R., \& Davies, R. S. (2013). The nature of adolescent learner interaction in a virtual high school setting. Journal of Computer Assisted Learning, 29(2), 153-167. https://doi.org/10. $1111 /$ j.1365-2729.2012.00479.x 
Borup, J., Graham, C. R., \& Drysdale, J. S. (2014a). The nature of teacher engagement at an online high school. British Journal of Educational Technology, 45(5), 793-806. https://doi.org/10.1111/bjet.12089

Borup, J., West, R. E., Graham, C. R., \& Davies, R. S. (2014b). The adolescent community of engagement framework: A lens for research on K-12 online learning. Journal of Technology and Teacher Education, 22(1), 107-129 https://www.learntechlib.org/ $\mathrm{p} / 112371$

Burdina, G. M., Krapotkina, I. E., \& Nasyrova, L. G. (2019). Distance learning in elementary school classrooms: An emerging framework for contemporary practice. International journal of instruction, 12(1), 1-16. https://doi.org/10.29333/iji.2019.1211a.

Cavanaugh, C. (2013). Student achievement in elementary and high school. In handbook of distance education (pp. 188-202). Routledge.

Cavanaugh, C., Barbour, M. K., \& Clark, T. (2009). Research and practice in K-12 online learning: A review of open access literature. The international review of research in open and distance learning, 10(1), 1-22. https://doi.org/10.19173/irrodl.v10i1.607.

Charmaz, K. (2006). Constructing grounded theory: A practical guide through qualitative analysis. Sage Publications.

Curtis, H., \& Werth, L. (2015). Fostering student success and engagement in a K-12 online school. Journal of Online Learning Research, 1(2), 163-190 https://www.learntechlib.org/primary/p/150962/

Darling-Hammond, L., Schachner, A., \& Edgerton, A. K. (2020). Restarting and reinventing school: Learning in the time of COVID and beyond. Learning Policy Institute.

DeWitt, J. (2017). District-level blended learning implementation: Readiness points and challenges. Michigan Virtual University. https://mvlri.org/wp-content/uploads/2017/09/Blended-ModelPilot-Study.pdf

Dibner, K. A., Schweingruber, H. A., \& Christakis, D. A. (2020). Reopening K-12 schools during the COVID-19 pandemic: A report from the national academies of sciences, engineering, and medicine. Jama, 324(9), 833-834. https://doi.org/10.1001/jama.2020.10175

Digital Learning Collaborative. (2020). The annual report of the digital learning collaborative. Digital Learning Collaborative. https:// static1.squarespace.com/static/59381b9a17bffc68bf625df4/t/ 5 eac543b241d767eb9c362db/1588352075868/DLC-KPSnapshot $2020+\% 281 \% 29$.pdf

Education Week. (2020, November 15). Map: Coronavirus and school closures. https://www.edweek.org/ew/section/multimedia/mapcoronavirus-and-school-closures.html

Farmer, T., \& West, R. (2019). Exploring the concerns of online K-12 teachers. Journal of Online Learning Research, 5(1), 97-118 https:// www.learntechlib.org/primary/p/184482/Education Week. (2020, November 15). Map: Coronavirus

Fauzi, I., \& Khusuma, I. (2020). Teachers' elementary school in online learning of COVID-19 pandemic condition. Jurnal Iqra': Kajian Ilmu Pendidikan, 5(1). 58-70. https://doi.org/10.25217/ji.v5i1.914

Fox, C., \& Jones, R. (2019). State K-12 broadband leadership 2019: Driving connectivity, access, and student success. State Educational Technology Directors Association. https://www.ena. com/wp-content/uploads/setda-broadband-state-leadership-2019. pdf

Gemin, B., \& Pape, L. (2017). Keeping pace with K-12 online learning. Evergreen Education Group. https://files.eric.ed.gov/fulltext/ ED576762.pdf

Guernsey, L. (2012) Screen time: How electronic media-From baby videos to educational software-Affects your young child. Basic Books.
Hawkins, A., Graham, C. R., Sudweeks, R. R., \& Barbour, M. K. (2013). Academic performance, course completion rates, and student perception of the quality and frequency of interaction in a virtual high school. Distance Education, 34(1), 64-83. https://doi.org/10.1080/ 01587919.2013 .770430

Kim, J. (2020). Learning and teaching online during Covid-19: Experiences of student teachers in an early childhood education practicum. International Journal of Early Childhood, 52(2), 145158. https://doi.org/10.1007/s13158-020-00272-6

Kolb, S. M. (2012). Grounded theory and the constant comparative method: Valid research strategies for educators. Journal of Emerging Trends in Educational Research and Policy Studies, 3(1), 83-86 https://citeseerx.ist.psu.edu/viewdoc/download?doi=10.1.1.301. $9451 \&$ rep=rep $1 \&$ type $=$ pdf

Lee, J. (2016). Early learning and educational technology policy brief. Office of Educational Technology, . https://tech.ed.gov/files/2016/ 10/Early-Learning-Tech-Policy-Brief.pdf

Lee, M., \& Figueroa, R. (2012). Internal and external indicators of virtual learning success: A guide to success in K-12 virtual learning. Distance Learning, 9(1), 21-28.

Lee, E., Pate, J. A., \& Cozart, D. (2015). Autonomy support for online students. TechTrends, 59(4), 54-61. https://doi.org/10.1007/ s11528-015-0871-9

Lin, C. H., Zheng, B., \& Zhang, Y. (2017). Interactions and learning outcomes in online language courses. British Journal of Educational Technology, 48(3), 730-748. https://doi.org/10.1111/ bjet.12457

Linton, J. (2016). Electronic learning communities as a support for building relationships with students in a statewide virtual high school. Journal of Online Learning Research, 2, 419-445 https://www. learntechlib.org/j/JOLR

Moore, M. G. (1989). Three types of interaction. The American Journal of Distance Education, 3(2), 1-6. https://doi.org/10.1080/ 08923648909526659

Muirhead, W. (2000). Online education in schools. The International Journal of Educational Management, 14(7), 315-324.

Murphy, E., \& Rodriguez-Manzanares, M. (2009). Teachers' perspectives on motivation in high-school distance education. Journal of Distance Education, 23(3), 1-24 http://www.jofde.ca/index.php/ jde/article/view/602

Murphy, E., Rodríguez-Manzanares, M. A., \& Barbour, M. (2011). Asynchronous and synchronous online teaching: Perspectives of Canadian high school distance education teachers. British Journal of Educational Technology, 42(4), 583-559. https://doi.org/10. 1111/j.1467-8535.2010.01112.x

Oliver, K., Osborne, J., \& Brady, K. (2009). What are secondary students' expectations for teachers in virtual school environments? Distance Education, 30(1), 23-45. https://doi.org/10.1080/ 01587910902845923

Project Tomorrow (2020a). 2020-90 days that changed $k$-12 teaching $\&$ learning: The shift to digital learning. https://tomorrow.org/ speakup/2020-90-Days-That-Changed-K-12-Teaching-Learning. html

Project Tomorrow (2020b). Digital learning during the pandemic: Emerging evidence of an education transformation. https:// tomorrow.org/speakup/pdfs/2020\%20Speak\%20Up\%20National\% 20Report.pdf

Salmon, G. (2011). E-moderating: The key to teaching and learning online (3rd ed.). Routledge.Schleicher, A. (2020, September 8). The impact of covid-19 on education. OECD. https://www.oecd.org/ education/the-impact-of-covid-19-on-education-insights-educationat-a-glance-2020.pdf 
Swan, K. (2001). Virtual interaction: Design factors affecting student satisfaction and perceived learning in asynchronous online courses. Distance Education, 22(2), 306-331. https://doi.org/10.1080/ 0158791010220208

U.S. Office of Educational Technology (2021). Teacher digital learning guide. https:/tech.ed.gov/files/2021/01/Teacher-Digital-LearningGuide.pdf

Velasquez, A., Graham, C. R., \& West, R. E. (2013). An investigation of practices and tools that enabled technology-mediated caring in an online high school. The International Review of Research in Open and Distance Learning, 14(5), 277-299.

Vygotsky, L. S. (1978). Mind in society. Harvard University Press.

Wagner, E. D. (1997). Interactivity: From agents to outcomes. New Directions for Teaching and Learning, 1997(71), 19-26 https:// doi.org/10.1002/tl.7103

Weiner, C. (2003). Key ingredients to online learning: Adolescent students study in cyberspace - The nature of the study. International
Journal on E-Learning, 2(3), 44-50 https://www.learntechlib.org/ primary $/ \mathrm{p} / 14497$

Wicks, M. (2010). A national primer on K-12 online learning: Version 2. International association for K-12 online learning. https://aurorainstitute.org/wp-content/uploads/iNCL_NationalPrimerv22010web1.pdf

Willingham, D. (2017). Ask the cognitive scientist: Do manipulatives help students learn. American Educator, 41(3), 25-40 https:// www.aft.org/sites/default/files/periodicals/ae_fall2017_willingham. pdf

Zhu, M., \& Bonk, C. J. (2019). Designing MOOCs to facilitate participant self-monitoring for self-directed learning. Online Learning, 23(4), 106-134 https://doi.org/10.24059/olj.v23i4.2037

Publisher's Note Springer Nature remains neutral with regard to jurisdictional claims in published maps and institutional affiliations. 